\title{
Time Series Analysis
}

National Cancer Institute

\section{Source}

National Cancer Institute. Time Series Analysis. NCI Thesaurus. Code C18235.

There are two main goals of time series analysis: (a) identifying the nature of the phenomenon represented by the sequence of observations, and (b) forecasting (predicting future values of the time series variable). 